This item was submitted to Loughborough's Research Repository by the author.

Items in Figshare are protected by copyright, with all rights reserved, unless otherwise indicated.

\title{
The analysis of UK road traffic accident data and its use in the development of a direct vision standard for trucks in London
}

PLEASE CITE THE PUBLISHED VERSION

https://doi.org/10.1007/978-3-030-20503-4_39

\section{PUBLISHER}

(C) Springer

\section{VERSION}

AM (Accepted Manuscript)

\section{PUBLISHER STATEMENT}

The final authenticated version is available online at https://doi.org/10.1007/978-3-030-20503-4_39.

\section{LICENCE}

CC BY-NC-ND 4.0

\section{REPOSITORY RECORD}

Marshall, Russell, Steve Summerskill, and James Lenard. 2019. "The Analysis of UK Road Traffic Accident Data and Its Use in the Development of a Direct Vision Standard for Trucks in London". Loughborough University. https://hdl.handle.net/2134/37779. 


\title{
The Analysis of UK Road Traffic Accident Data and its Use in the Development of a Direct Vision Standard for Trucks in London
}

\author{
Russell Marshall ${ }^{1}$, Steve Summerskill ${ }^{1}$ \\ and James Lenard ${ }^{1}$ \\ ${ }^{1}$ Loughborough Design School, Loughborough Univerity, \\ Loughborough, LE11 3TU, UK \\ \{R.Marshall, S.J.Summerskill2, J.A.Lenard\}@1boro.ac.uk
}

\begin{abstract}
This paper presents the analysis of UK road accident data to inform the development of a Direct Vision Standard (DVS) for trucks in the UK. The research forms part of a project funded by Transport for London. The DVS allows any truck to be rated in terms of its performance in the field of view afforded the driver. The standard will be used to limit the movement of poorly rated vehicles within central London from 2020. The standard will also foster improved truck designs for direct vision in the future. The analysis used accident data from the UK STATS 19 database between 2010 and 2015. Data were categorized on causation data and a series of accident characteristics to identify scenarios of accidents between trucks and vulnerable road users. These scenarios then informed the design of the DVS, in particular the definition of the areas of greatest risk around the cab.
\end{abstract}

Keywords: Vehicle design - Simulation - Direct Vision Standard · Safety · Regulation

\section{$1 \quad$ Introduction}

In recent years road safety has improved in the UK. 2012 saw the lowest ever number of fatalities through road accidents (1637) a 49\% reduction since 2000. Those killed and seriously injured (KSI) saw a reduction of $40 \%$ in the same period. Contrary to this there has been an increase in accidents involving Vulnerable Road Users (VRUs), typically pedal cyclists and pedestrians. Between 2000 and 2012 cyclist KSI casualties increased by $21 \%$. In London the issue is more pronounced with a reduction in overall KSI casualties of $51 \%$ contrasted with a $59 \%$ increase in cyclist KSI casualties [1].

In accidents involving a VRU a disproportionate number involve a collision with a Heavy Goods Vehicles (HGVs). In 2015 20\% of pedestrian fatalities and $78 \%$ of cyclist fatalities in London involved a $\mathrm{HGV}$, despite them accounting for only $4 \%$ of road miles [2]. 
In 2011 research performed by Loughborough Design School (LDS) identified a major blind spot in HGV driver's vision and led to a revision of UNECE Regulation 46 that mandates the field of view of HGV mirrors [3]. The work also discussed the difficulties faced by HGV drivers in gaining situational awareness of VRUs around the cab and highlighted the need form improved direct vision. In 2015 further research into the field of view afforded the driver of HGVs on UK roads identified the variability in the ability for drivers to see VRUs in proximity of the vehicle. This highlighted the need for some form of standard for direct vision performance of these vehicles [4]. In 2016 the Mayor of London announced the 'vision zero' approach and the aim to implement a Direct Vision Standard (DVS) [5].

This paper presents research funded by Transport for London into the development of a DVS. Building upon established techniques the standard exploits a volumetric projection of the field of view afforded the driver through the vehicle's windows. These volumetric projections are then intersected with an assessment volume around the cab. The assessment volume represents the critical areas around the vehicle that the driver needs to be able to see. The amount of the assessment volume that can be seen by the driver provides an objective measure of direct vision performance of the vehicle. This measure allows vehicle performance to be compared and given a performance rating against a zero to five-star scale, with the worst performing vehicles rated as zero star and the best as five star. The specific focus of this paper is to explore the analysis of UK accident data to inform the definition of the assessment zone around the vehicle. It was important given the DVS's aim in rating and fostering improved direct vision of VRUs that the assessment zone was representative of where the driver needed to be able to see in order to gain situational awareness of any VRUs in proximity to the cab, otherwise deemed to be the area of 'greatest risk'.

\section{Accident Data Analysis}

Accident data were sourced via the UK's STATS 19 database. STATS 19 is the UK road accident database compiled from Police records. STATS 19 is maintained by the UK Department for Transport. The analysis was performed for all accidents between 2010 and 2015. This time period was selected due the quality of the data that are available for that date range compared to earlier data. This resulted in a total of 2443 accidents Nationally.

Each database record represents an accident, recorded by a police officer using the STATS 19 accident form when someone has been injured or killed on the highway. In documenting the accident aspects of the indecent are categorized and documented under various field headings. The categories then provide a means to interrogate the data.

One of the more potentially useful categories is the data on accident causation, where the police attending the scene indicate the contributory factors in the accident. These are special fields in the database, not commonly available and had to be requested by the researchers. From the broad range of data fields available the following were explored for this research:

- Contributory factor: accident causation data (e.g. blind spot, did not look properly etc.) 
- Accident severity: the severity of the accident (fatal, serious or slight)

- Vehicle_type; The vehicles and other people involved (e.g. HGVs above 7.5 tonnes, pedestrian, cyclist)

- Police force: the locale of the Police force which has captured the data which allows a comparison of the data in London and nationally

- First_point_of_impact: first point of contact between the vulnerable road user and the vehicle (e.g. front, offside etc.)

- Towing_and_articulation: category of vehicle (e.g. rigid or articulated)

- Vehicle_manoeuvre: the manoeuvre being performed when the accident occurred (e.g. turning left, going ahead)

- Junction_detail: road junction type

- Make; Year_of_lst reg: vehicle make and year of first registration

- Speed limit: speed limit on the road where the accident occurred

- Weather_conditions; Light_conditions: environmental conditions (e.g. fine, rain, fog, daylight, darkness - lights lit etc.)

- Age: age of the casualty

\subsection{Accident Severity between HGVs and VRUs}

The first interrogation of the data explored the severity of the accidents that had occurred overall, including all vehicle types, and those specifically between VRUs and HGVs.

Table 1 shows the breakdown of accidents by the three severity categories for all accidents between 2010 and 2015, and those specifically involving collisions between HGVs and pedestrians and HGVs and cyclists. For accidents involving collisions with HGVs it is clear to see that the severity is significantly increased. KSI causalities overall account for $13 \%$ of accidents, however for cyclists KSIs account for $31 \%$ of accidents and for pedestrians KSIs make up $47 \%$ of accidents. Thus, the consequences of a VRU being involved in a collision with a HGV are much more severe.

Table 1. Severity of accidents for all accidents and for those specifically including HGVs and VRUs.

\begin{tabular}{|l|c|c|c|}
\hline & \multicolumn{3}{|c|}{ Severity } \\
\cline { 2 - 4 } & Slight & Serious & Fatal \\
\hline All accidents & $87 \%(162340)$ & $12 \%(22137)$ & $1 \%(1732)$ \\
\hline HGVs and cyclists & $64 \%(773)$ & $23 \%(336)$ & $8 \%(93)$ \\
\hline HGVs and pedestrians & $53 \%(653)$ & $29 \%(362)$ & $18 \%(226)$ \\
\hline
\end{tabular}

\subsection{Causation of Accidents between HGVs and VRUs}

Causation data does not form part of the normal data available in the STATS 19 database and is only available by request from the Department for Transport. The data represent the judgement of the police attending the scene as to the probable casual factors for the accident. Due to the large number of these factors only those that account for the top $95 \%$ of accidents are shown in Table 2. In both cases the most prev- 
alent causation factor is failed to look properly. Vehicle blind spot also features highly being the second most prevalent causation far for collisions with pedestrians and the sixth most prevalent for collisions with cyclists.

Table 2. Causation data for the top $95 \%$ of accidents Nationally between HGVs above $7.5 \mathrm{t}$ and cyclists (left) and between HGVs above 7.5t and pedestrians (right).

\begin{tabular}{|c|c|c|c|}
\hline \multicolumn{2}{|r|}{ Accidents between HGVs and cyclists } & \multicolumn{2}{|c|}{ Accidents between HGVs and pedestrians } \\
\hline $\begin{array}{c}\text { No. of } \\
\text { accidents }\end{array}$ & Causation category & $\begin{array}{c}\text { No. of } \\
\text { accidents }\end{array}$ & Causation category \\
\hline 723 & \begin{tabular}{|l|} 
Failed to look properly \\
\end{tabular} & 284 & \begin{tabular}{|l|} 
Failed to look properly \\
\end{tabular} \\
\hline 357 & Failed to judge other person's path or speed & 125 & Vehicle blind spot \\
\hline 321 & Passing too close to cyclist & 105 & Poor turn or manoeuvre \\
\hline 257 & Poor turn or manoeuvre & 101 & Passing too close to horse rider or pedestrian \\
\hline 219 & Careless, reckless or in a hurry & 80 & Careless, reckless or in a hurry \\
\hline 159 & Vehicle blind spot & 50 & Failed to judge other person's path or speed \\
\hline 77 & Loss of control & 39 & Other-Please specify below \\
\hline 58 & Cyclist entering road from pavement & 31 & Overloaded or poorly loaded vehicle or trailer \\
\hline 39 & Cyclist wearing dark clothing at night & 26 & Stationary or parked vehicle(s) \\
\hline 36 & Following too close & 23 & Road layout (e.g. bend) \\
\hline 34 & Other - Please specify below & 12 & Temporary road layout (e.g. contraflow) \\
\hline 33 & Swerved & 12 & Vehicle travelling along pavement \\
\hline 28 & Road layout (e.g. bend) & 11 & Disobeyed pedestrian crossing facility \\
\hline 27 & Junction restart (moving off at junction) & 11 & Junction restart (moving off at junction) \\
\hline 26 & Vehicle door opened or closed negligently & 10 & Travelling too fast for conditions \\
\hline 24 & Travelling too fast for conditions & 9 & Aggressive driving \\
\hline 23 & Not displaying lights at night / poor visibility & 8 & Illegal turn or direction of travel \\
\hline 22 & Failed to signal or misleading signal & 8 & Swerved \\
\hline 21 & Dazzling sun & 7 & Distraction outside vehicle \\
\hline 19 & Disobeyed 'Give Way' or 'Stop' sign & 6 & Road layout (e.g. hill crest) \\
\hline 18 & Impaired by alcohol & 6 & Rain \\
\hline 17 & Sudden braking & 6 & Sudden braking \\
\hline 16 & Stationary or parked vehicle(s) & 6 & Dazzling sun \\
\hline 16 & Slippery road (due to weather) & 6 & Slippery road (due to weather) \\
\hline 16 & Disobeyed automatic traffic signal & 5 & Loss of control \\
\hline 15 & Nervous & 5 & Vehicle door opened or closed negligently \\
\hline 15 & Aggressive driving & 4 & Animal or object in carriageway \\
\hline 12 & Rain, sleet, snow or fog & 4 & Poor or defective road surface \\
\hline 11 & Vehicle travelling along pavement & 4 & Junction overshoot \\
\hline 10 & Junction overshoot & 4 & Exceeding speed limit \\
\hline 10 & Learner or inexperienced driver/rider & 4 & Driver using mobile phone \\
\hline 10 & Poor or defective road surface & 4 & Distraction in vehicle \\
\hline 10 & Fatigue & 3 & Vegetation \\
\hline
\end{tabular}

As these data are coded by a police officer after the accident has taken place it is possible that some accidents coded as 'failed to look properly' involved a blind spot. However, there is no way to be able to know for certain. Regardless, in cases the combination of both vision issues (failed to look + blind spot) represent nearly $37 \%$ of all accidents coded with a causation factor for collisions with cyclists and nearly $33 \%$ of all accidents coded involving pedestrians. This was further explored for accidents occurring in London as shown in Table 3. In both types of accident 'vehicle blind spot' is the most prevalent causation factor followed by 'failed to look properly'. Thus, whether Nationally or within London the causation data has highlighted that the 
lack of ability for HGV drivers to see VRUs is a significant contributory factor in accidents.

Table 3. Causation data of accidents in London between HGVs above $7.5 \mathrm{t}$ and cyclists (left) and between HGVs above $7.5 \mathrm{t}$ and pedestrians (right).

\begin{tabular}{|c|l|c|c|l|}
\hline \multicolumn{2}{|c|}{ Accidents between HGVs and cyclists } & \multicolumn{2}{c|}{ Accidents between HGVs and pedestrians } \\
\hline $\begin{array}{c}\text { No. of } \\
\text { accidents }\end{array}$ & \multicolumn{1}{|c|}{ Causation category } & & $\begin{array}{c}\text { No. of } \\
\text { accidents }\end{array}$ & \multicolumn{1}{c|}{ Causation category } \\
\hline $\mathbf{8 4}$ & Vehicle blind spot & & $\mathbf{4 7}$ & Vehicle blind spot \\
\hline $\mathbf{4 8}$ & Failed to look properly & & $\mathbf{2 1}$ & Failed to look properly \\
\hline 21 & Passing too close to cyclist & 4 & Junction restart (moving off at junction) \\
\hline 16 & Careless & 4 & Passing too close to cyclist \\
\hline 14 & Failed to judge other person's path or speed & & 3 & Poor turn or manoeuvre \\
\hline 12 & Poor turn or manoeuvre & 3 & Careless \\
\hline 4 & Failed to signal or misleading signal & 2 & Temporary road layout (e.g. contraflow) \\
\hline 3 & Vehicle door opened or closed negligently & & 1 & Stationary or parked vehicle(s) \\
\hline 1 & Buildings & 1 & Illegal turn or direction of travel \\
\hline 1 & Aggressive driving & & \\
\hline 1 & Swerved & & \\
\hline
\end{tabular}

To add further context, in accidents involving HGVs and cyclists and in which blind spot was recorded as a causation factor $90 \%$ of accidents occurred in daylight, $94 \%$ occurred in fine weather and $90 \%$ occurred on roads with a speed limit of $30 \mathrm{mph}$ or lower. For accidents involving HGVs and pedestrians, 94\% occurred in daylight, $93 \%$ in fine weather, $95 \%$ on roads with a speed limit of $30 \mathrm{mph}$ or lower, and $60 \%$ occurred at some form of pedestrian crossing. This suggests that the blind spot causations cannot be attributed to poor visibility due to environmental factors and that the majority of these accidents are occurring at relatively low speeds.

\subsection{First Point of Contact and Vehicle Manoeuvre for Accidents where Blind Spot was Reported as the Causation Factor}

In order to understand more about the nature of accidents where vehicle blind spot was reported as the causation factor the first point of impact data were interrogated. These data highlight the location of the VRU with respect to the HGV at the point of impact and provide some insight into whether they should have been visible to the driver. In the case of pedestrians, assumed to be relatively slow moving, they highlight the locations adjacent to the vehicle in which the pedestrian should have been seen by a driver using either direct vision through the windows or indirect vision through the mirrors. For cyclists, the potential variation in the speed of the cyclist makes the interpretation of accident scenarios more uncertain. If, for example, the first point of contact is the nearside (passenger side) of the cab there are two example accident scenarios considered. The first is that the cyclist was stationary or moving slowly next to the HGV at the point of impact and thus not seen by the driver in the Class V (passenger side, look-down) mirror or through the passenger side windows. The second is that the cyclist was approaching the HGV from the rear down the lefthand side of the cab at a higher speed and not seen in either the Class II or Class IV (passenger side, rear view) mirrors. The first situation can potentially be improved by 
better direct vision, the second is unlikely to be affected by improved direct vision and instead will rely upon the ability of the driver to look in the passenger side mirrors at the correct time to see the cyclist.

Table 4 shows the National data for first point of contact between HGVs and cyclists and HGV and pedestrians for accidents in which vehicle blind spot was the causation factor. Only those areas in which direct vision could potentially play a role were included i.e. to the front, offside (driver's side) or nearside (passenger side). What these data highlight is that for cyclists the main blindspot (70\%) is to the nearside (passenger side) of the vehicle and for pedestrians it is to the front (46\%) of the vehicle.

Table 4. Accidents Nationally with the first point of contact to the front, offside or nearside of the vehicle between HGVs above 7.5t and cyclists (left) and between HGVs above 7.5t and pedestrians (right) where blind spot was reported as the causation factor.

\begin{tabular}{|l|c|c|c|c|}
\hline & \multicolumn{4}{|c|}{ First point of contact } \\
\cline { 2 - 5 } & Cyclist (n) & Cyclist (\%) & Pedestrian (n) & Pedestrian (\%) \\
\hline Front & 22 & 15 & 54 & $\mathbf{4 6}$ \\
\hline Driver's side & 15 & 5 & 9 & 8 \\
\hline Passenger side & 104 & $\mathbf{7 0}$ & 34 & 29 \\
\hline Total & 141 & 90 & 97 & 82 \\
\hline
\end{tabular}

The cyclist and pedestrian data were then combined to produce percentages of accidents to the front, nearside and offside of the vehicle as shown in Fig. 1.

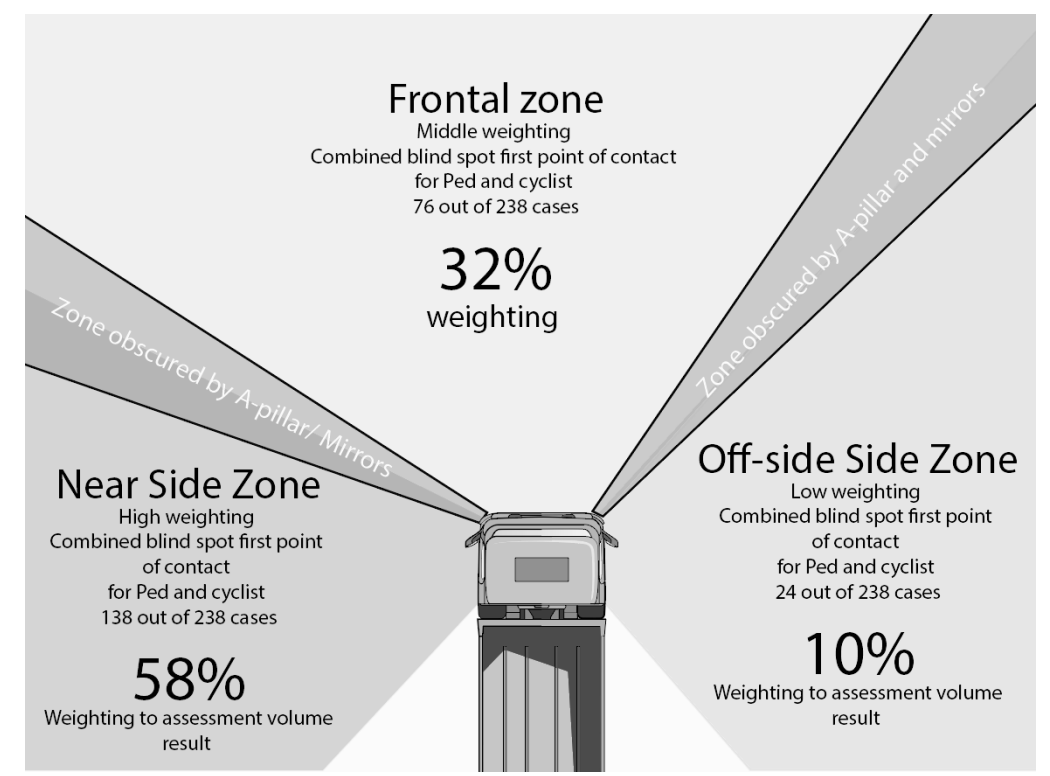

Fig. 1. The combined percentage of National accidents between HGVs and VRUs in which blindspot was reported as a causation factor showing first point of contact to the front, near and offsides. 
The vehicle manoeuvre data are shown in Table 5 for accidents between HGVs and VRUs in which blind spot was recorded as the causation factor. When these data are combined with the first point of contact above two clear scenarios present themselves. The first involves HGVs turning to the left and colliding with a cyclist to the nearside. The second involves HGVs moving off and colliding with pedestrians to the front.

Table 5. Vehicle manoeuvre in accidents between HGVs above $7.5 \mathrm{t}$ and cyclists (left) and between HGVs above 7.5t and pedestrians (right) in which blind spot was recorded as the causation factor.

\begin{tabular}{|c|c|l|c|c|c|l|}
\hline \multicolumn{5}{|c|}{ Vehicle manoeuvre prior to accident } \\
\hline \multicolumn{2}{|c|}{ Accidents between HGVs and cyclists } & \multicolumn{2}{c|}{ Accidents between HGVs and pedestrians } \\
\hline $\begin{array}{c}\text { No. of } \\
\text { accidents }\end{array}$ & $\%$ & \multicolumn{1}{|c|}{ Manoeuvre } & $\begin{array}{c}\text { No. of } \\
\text { accidents }\end{array}$ & $\%$ & \multicolumn{1}{c|}{ Manoeuvre } \\
\hline 71 & 47 & Turning left & & 52 & 42 & Moving off \\
\hline 20 & 13 & Going ahead other & 25 & 20 & Reversing \\
\hline 19 & 13 & Moving off & 16 & 13 & Going ahead other \\
\hline 13 & 9 & Overtaking moving vehicle - offside & & 15 & 12 & Turning left \\
\hline 10 & 7 & Turning right & 9 & 7 & Turning right \\
\hline 6 & 4 & Parked & & 2 & 2 & Waiting to go - held up \\
\hline 3 & 2 & Changing lane to left & & 2 & Waiting to turn left \\
\hline 3 & 2 & Going ahead left-hand bend & 1 & 1 & U-turn \\
\hline 2 & 1 & Waiting to go - held up & & 1 & Going ahead right-hand bend \\
\hline 1 & 1 & Reversing & & & \\
\hline 1 & 1 & Slowing or stopping & & & & \\
\hline 1 & 1 & U-turn & & & \\
\hline 1 & 1 & Overtaking static vehicle - offside & & & \\
\hline 1 & 1 & Overtaking - nearside & & & \\
\hline
\end{tabular}

\subsection{Age of the VRU}

The final data of interest that emerged from the analysis concerned the age of the VRUs involved in accidents. Fig. 2 shows the ages of VRUs involved in accidents with HGVs in which blind spot was recorded as the causation factor. In the case of cyclists the peak is around 25 years as might be expected when considering the demographic of cyclists. It can also be seen that there is a significant rise in the accidents involving pedestrians over the age of 60 . However, there is no reason that pedestrian VRUs involved in accidents should have a higher prevalence of over 60s. Considering the accident scenario identified for pedestrians earlier (collision to front with HGV moving off), it can be inferred that there is the potential for older people to be crossing in front of the HGV and unable to move out of the way when the HGV begins to move off. 


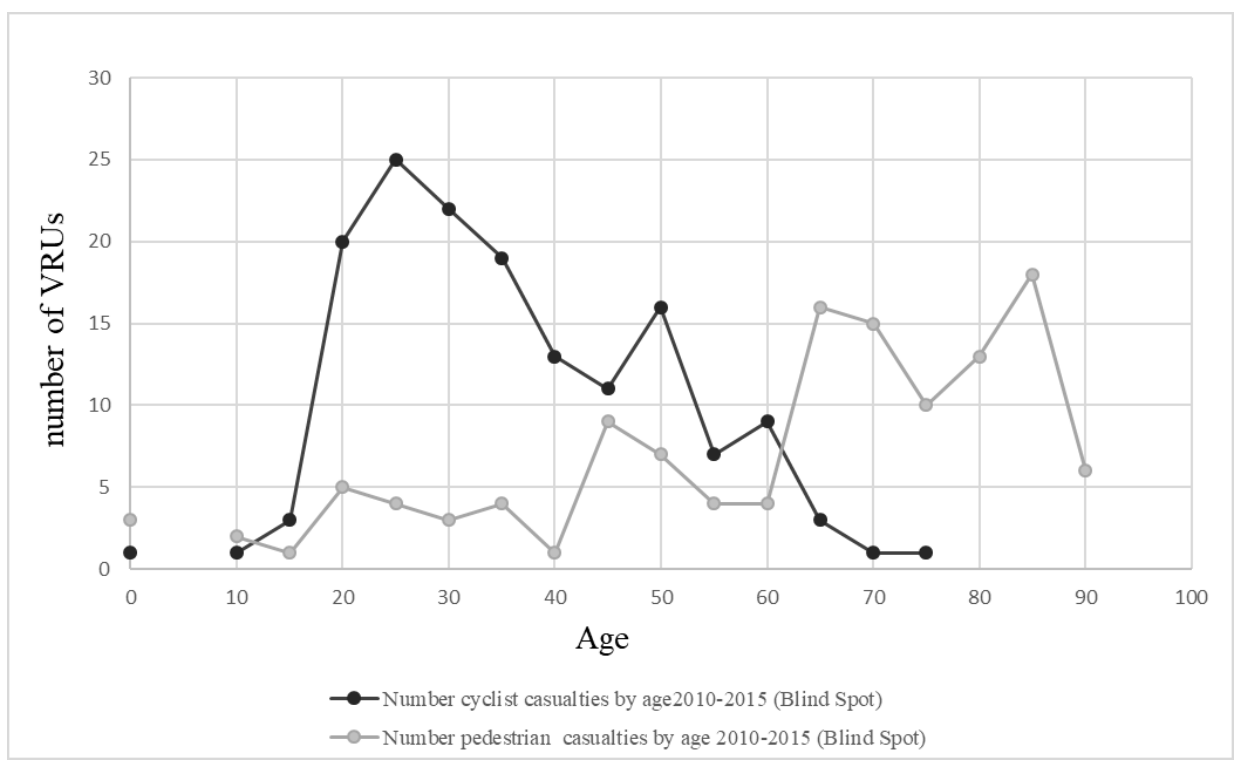

Fig. 2. The number of VRUs involved in accidents with HGVs, by age, where blind spot was recorded as the contributory factor

\section{The Direct Vision Standard}

A more thorough presentation of the DVS is detailed elsewhere. However, a brief over view will be given below to provide a context for the use of the accident data analysis and how it was used to inform the development of the DVS.

The DVS utilizes a volumetric projection technique first developed in the digital human modelling tool SAMMIE [3,4,6,7] shown in Fig. 3 . For the DVS this volumetric approach was developed to be able to be used in any 3D CAD software in order to ensure all relevant stakeholders such as vehicle manufacturers and testing organizations had the greatest chance of being able to implement the DVS for their own needs without bespoke software tools. Where previous implementations of this approach were used to produce projections on surfaces such as the floor or onto the surface of a sphere, the DVS had to be able to evaluate the critical area that needed to be seen by the driver in the context of VRU safety. In order to provide this evaluation an 'assessment volume' was proposed around the HGV. The projected volumes from the windows would then be intersected with the assessment volume to provide a series of volumes that the driver could see in the area of the assessment volume as shown in Fig. 4. These visible volumes could then be quantified in $\mathrm{mm}^{3}$ to provide an objective measure for direct vision. These measures also establish a means to rate vehicles and support manufacturers in optimizing direct vision for future vehicle design.

One of the key developments of the DVS was the configuration of the assessment zone. It was important that the assessment zone was representative of the area of greatest risk, the area in which accidents with VRUs occurred and thus the driver needed to be able to see. The starting point with this definition was the accident anal- 
ysis documented above. The analysis identified two key scenarios in which HGVs were involved in accidents with VRUs: collisions with cyclists to the nearside and collisions with pedestrians to the front. This mandated at least two areas of coverage around the cab, to the front and to the nearside. Whilst the offside only accounted for $10 \%$ of all accidents (Fig. 1) it was important that this area was also accounted for. What the accident analysis also highlighted was that accidents occurred in close proximity to the vehicle, at relatively low speeds and typically at junctions. This suggested that the driver needed to be able to see VRUs in close proximity to the cab, not far away where the accident occurred due to the high closing speed between the HGV and the VRU.

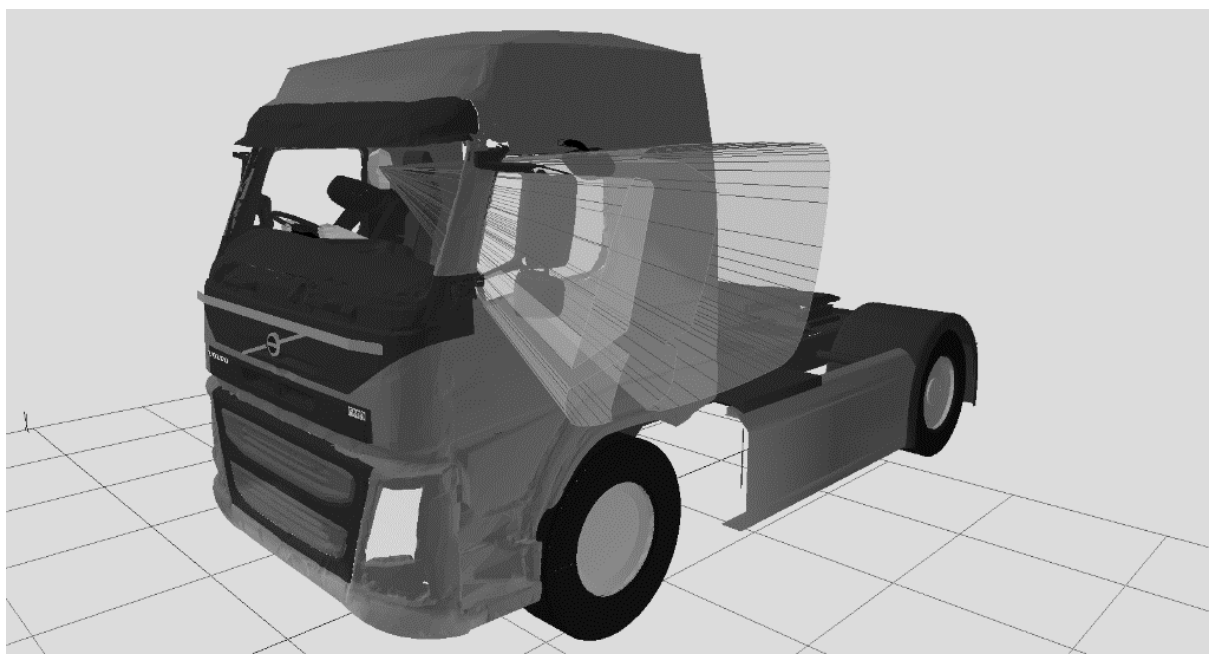

Fig. 3. Volumetric projection of the field of view afforded the driver through the nearside windows.

Based on these data the assessment volume shown in Fig. 4 was finally proposed. Its dimensions were ultimately goverened by the coverage of mirrors as mandated in UNECE Regulation 46 [8]. It may seem counter-intuitive to use an indirect vision specification to inform a direct vision standard, however it provides a rationale for how far direct vision should be assessed from the vehicle. If current vehicles are designed such that mirrors are required to cover up to $4.5 \mathrm{~m}$ from the passenger side of the cab it follows that direct vision should be afforded beyond this distance. The direct vision standard aims to remove the reliance on mirrors and thus should focus on providing direct vision of the areas currently covered by mirrors. The height of the assessment volume was determined to ensure that is encompassed the majority of the global poplulation and so the shoulder height of the $99^{\text {tho }} \%$ ile Dutch male (Globally, the tallest population) was used. This would provide an assessment volume that vertically included $99 \%$ of the global population.

In the final version of the DVS [9] the volumes are intersected with the assessment volumes and the remaining volume is calculated. However, in the development of this approach numerous weightings were explored in line with the accident data analysis. One of the key weighting investigated was the use of the three zones and the 
associated percentages for point of first contact shown in Fig. 1. In producing the volumes there are three discrete sets of projections, those through the windscreen, those through the offside windows and those through the nearside windows. This allows the volumetric totals to be calculated for those three directions independently. To explore the effect of weighting, the three directional totals were then multipled by the percentages from the accident data such that the front was multiplied by 0.32 , the offside by 0.1 and the nearside by 0.58 . The intention was that by weighting the results those vehicles that offered better direct vision of the more important areas would be rewarded and that greater coverage of a less critical area could not compensate for poor coverage of a more critical area.

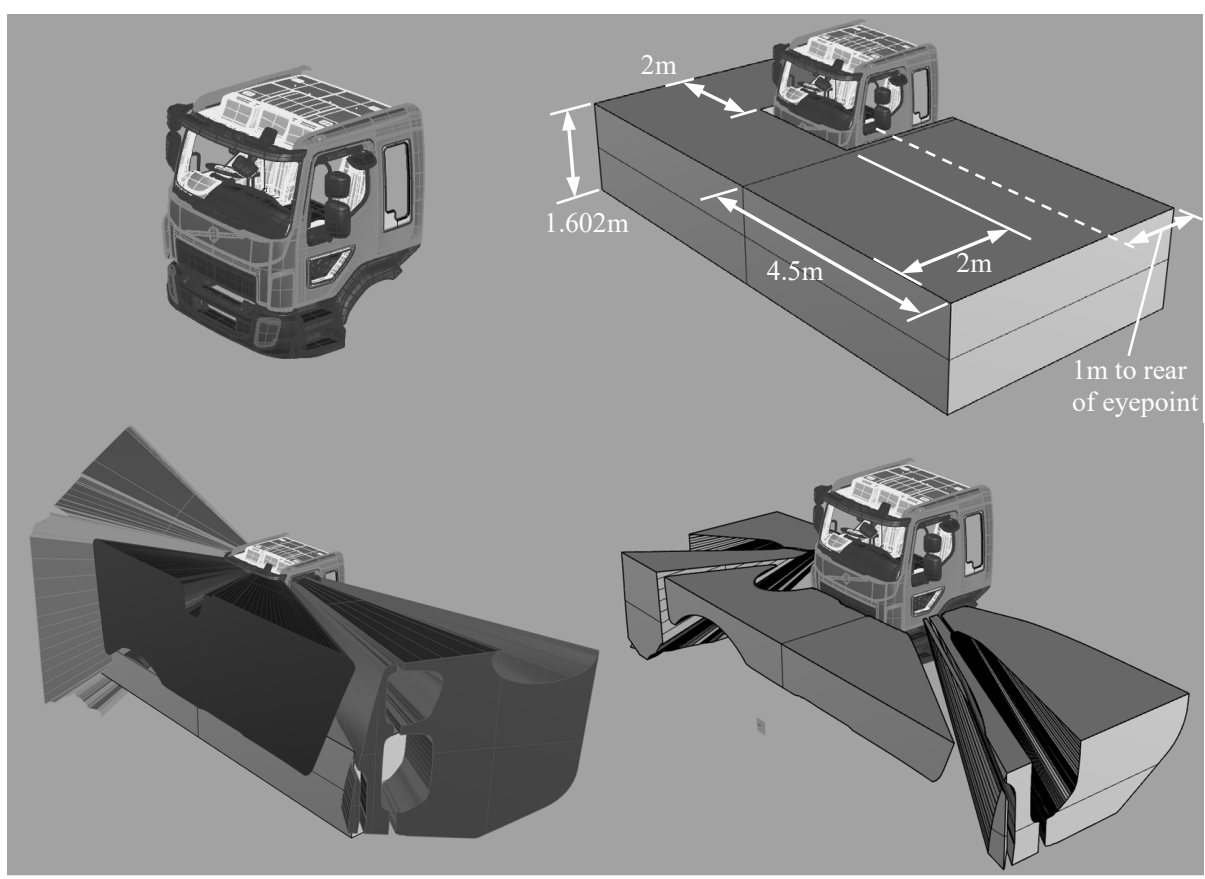

Fig. 4. Series of images showing the volumetric evaluation process. Imported HGV cab in Rhinoceros CAD software (top left), assessment volume aligned to cab (top right), direct vision volumes projected (bottom left), projections intersected with assessment volume (bottom right).

The results of the weighted volumes are shown in Fig. 5 (bottom). These can be compared to the unweighted results in Fig. 5 (top). This is only one of the weighting schemes explored but all weighting options exhibited the same issues. As can be seen in the figure, the results become more compressed for the majority of current vehicles on UK and EU roads. In light of these findings it was considered that the weighting whilst appropriate in principle did not offer sufficient differentiation between vehicle performance. Essentially the majority of the current vehicle fleet performed poorly. In order to enable operators to be able to discern differences in vehicle performance more clearly and to afford greater choice in purchasing decisions it was ultimately decided to select an unweighted assessment volume [8]. 


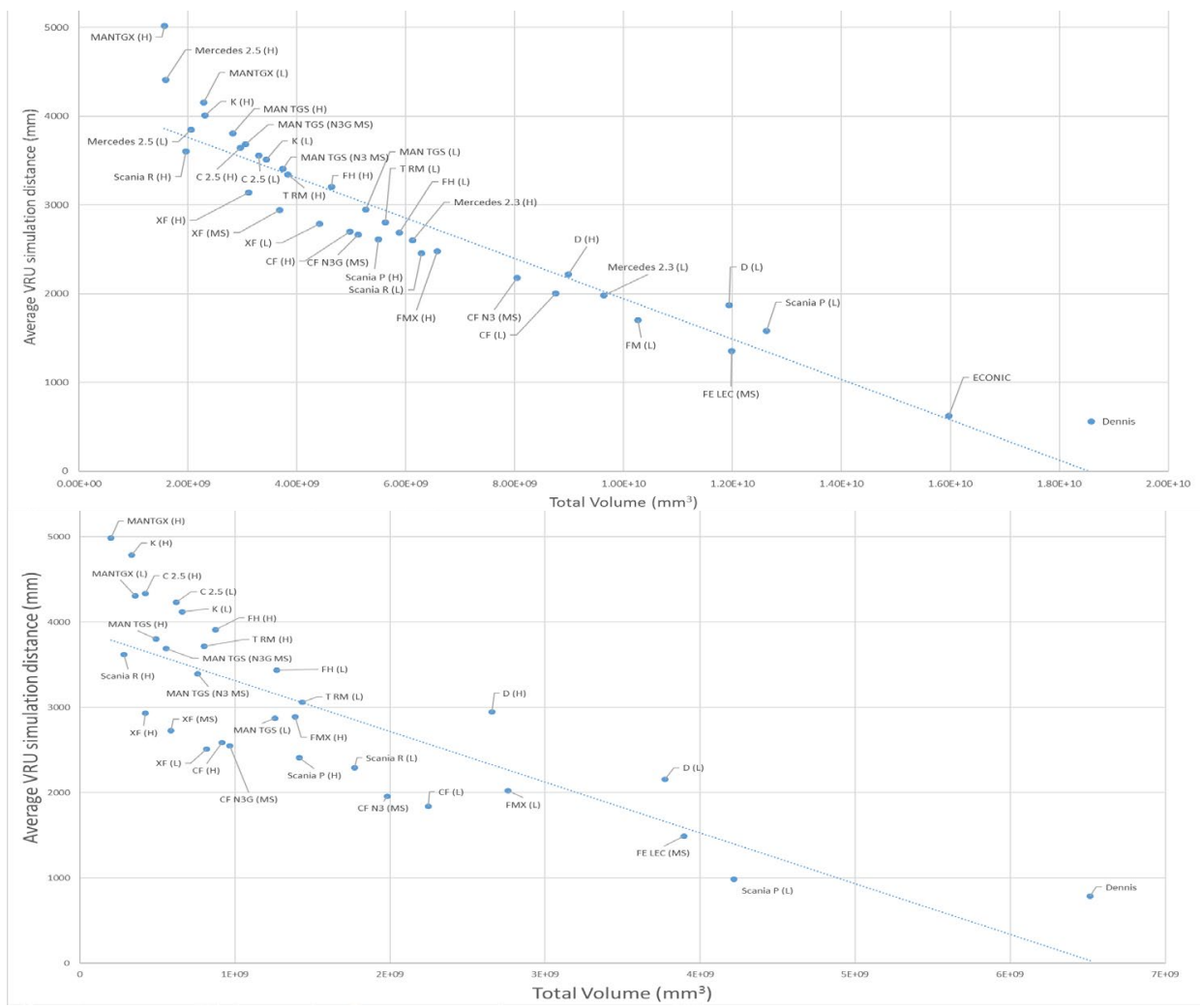

Fig. 5. Correlation graphs showing explorations of weighting the assessment volume. Top graph shows unweighted volumes correlated with the distance at which 13 VRU simulations can be placed adjacent to the cab with just their head and shoulders visible (a real world approximation of direct vision). Bottom graph shows the same correlation but with weighted volume scores.

\section{Conclusion}

An analysis of UK road traffic accident data from the UK STATS 19 database has been performed as part of research to develop a Direct Vision Standard for HGVs in London. Data between 2010 and 2015 were interrogated to explore accidents between HGVs greater than $7.5 \mathrm{t}$ and vulnerable road users, with specific causation data supplied from the UK Department for Transport. From the analysis a number of key findings were identified:

- The severity of accidents between HGVs and VRUs is much greater with $31 \%$ for cyclists and $47 \%$ for pedestrians being the most serious, compared to $13 \%$ for all accidents.

- The most common causation data is that the HGV driver failed to see the VRU and that confounding factors such as driving at nighttime and in poor weather were not significant. 
- Two accidents scenarios emerged: front collisions with pedestrians (vehicle pulling away) and nearside collisions with cyclists (vehicle turning left).

- The areas of greatest risk around the vehicle were identified with $58 \%$ of accidents to the nearside, $32 \%$ to the front and $10 \%$ to the offside.

- That the age of pedestrian casualties is disproportionally skewed to the older population.

These findings have informed the development of the DVS for London that is in the process of being implemented as part of a safer lorry scheme and part of the broader vision zero initiative. The DVS uses a volumetric projection technique to evaluate the field of view of the driver of the area of greatest risk around the vehicle. The results provide a means to rate any vehicle against a five star rating scheme allowing the best performing vehicles to be identified and selected by operators and to encourage manufacturers to improve direct vision performance. The DVS is also currently being explored for its potential to be adopted more widely within the European Union.

\section{References}

1. Talbot, R., Reed, S., Barnes, J., Thomas, P., Christie, N.: Pedal Cyclist Fatalities in London: Analysis of Police Collision Files (2007-2011). Research Report. Transport Safety Research Centre, Loughborough University, Centre for Transport Studies, University College London. URL: https://dspace.lboro.ac.uk/2134/16487 (2014).

2. Department for Transport.: Reported Road Casualties in Great Britain: 2015. Annual Report. Moving Britain Ahead (2016).

3. Cook, S.E., Summerskill, S., Marshall, R., et al.: The development of improvements to drivers' direct and indirect vision from vehicles. Phase 2. Loughborough University. Report for Department for Transport. URL: https://dspace.lboro.ac.uk/2134/8873 (2011).

4. Summerskill, S., Marshall, R., Paterson, A., Reed, S.: Understanding direct and indirect driver vision in heavy goods vehicles: Final report prepared on behalf of Transport for London. Loughborough: Loughborough University. URL: https://dspace.lboro.ac.uk/2134/8874 (2015).

5. Transport for London.: Vision Zero Action Plan. Taking Forward the Mayor's Transport Strategy. URL: http://content.tfl.gov.uk/vision-zero-action-plan.pdf (2018).

6. Marshall, R., Summerskill, S., Cook, S.: Development of a volumetric projection technique for the digital evaluation of field of view. Ergonomics, 56 (9), pp.1437-1450. URL: http://dx.doi.org/10.1080/00140139.2013.815805 (2013).

7. Summerskill, S., Marshall, R., Cook, S.E., Lenard, J.A., Richardson, J.H.: The use of volumetric projections in Digital Human Modelling software for the identification of large goods vehicle blind spots. Applied Ergonomics, 53, pt. A, pp.267-280. http://dx.doi.org/10.1016/j.apergo.2015.10.013 (2016).

8. UNECE Regulation 46.: Uniform Provisions for Devices for Indirect Vision and of Motor Vehicles with Regard to the Installation of these Devices. UN ECE Vehicle Regulations. (2009).

9. Summerskill, S. Marshall, R. Paterson, A. Eland, A., Lenard, J.: The Definition, Production and Validation of the Direct Vision Standard (DVS) for HGVs: Final report prepared on behalf of Transport for London. Loughborough: Loughborough University. URL: https://dspace.lboro.ac.uk/2134/36622 (2019). 